\title{
What can food-image tasks teach us about anorexia nervosa? A systematic review
}

\author{
E. Caitlin Lloyd ${ }^{1 *}$ and Joanna E. Steinglass ${ }^{2,3}$
}

\begin{abstract}
A salient feature of anorexia nervosa (AN) is the persistent and severe restriction of food, such that dietary intake is inadequate to maintain a healthy body weight. Experimental tasks and paradigms have used illness-relevant stimuli, namely food images, to study the eating-specific neurocognitive mechanisms that promote food avoidance. This systematic review, completed in accordance with PRISMA guidelines, identified and critically evaluated paradigms involving images of food that have been used to study AN. There were 50 eligible studies, published before March $10^{\text {th }}$ 2018, identified from Medline and PsychINFO searches, and reference screening. Studies using food imagebased paradigms were categorised into three methodologic approaches: neuropsychology, neurophysiology, and functional magnetic resonance imaging (fMRI). Paradigms were reviewed with a focus on how well they address phenomena central to AN. Across tasks, differences between individuals with AN and healthy peers have been identified, with the most consistent findings in the area of reward processing. Measuring task performance alongside actual eating behaviour, and using experimental manipulations to probe causality, may advance understanding of the mechanisms of illness in AN.
\end{abstract}

Keywords: Anorexia nervosa, Eating behaviour, Food stimuli, Eating disorders, Cognitive neuroscience, fMRI

\section{Plain English Summary}

A core feature of anorexia nervosa is the persistent limiting of calorie intake, or avoidance of eating, which results in a severely low body weight. Given the relevance of eating behaviour to anorexia nervosa, studies have often used tasks involving pictures of food to try and understand the factors that contribute to the illness. In this article, we review studies involving the presentation of food images, to highlight the approaches that have been most successful in furthering knowledge about AN. Studies to date have identified some differences among individuals with AN, but have had limited success in identifying underlying mechanisms of illness. We consider modifications to existing experimental designs that may address these limitations, in particular discussing methods that have been used to study eating behaviour in non-eating disorder populations. We conclude that when using food image tasks to develop a better understanding of anorexia nervosa, it is important to link

\footnotetext{
* Correspondence: el15519@bristol.ac.uk

${ }^{1}$ Centre for Exercise, Nutrition and Health Sciences, School for Policy Studies, University of Bristol, Bristol, UK

Full list of author information is available at the end of the article
}

actual eating behaviour to task outcomes, and to develop research based on more specific hypotheses.

\section{Background}

A core feature of anorexia nervosa (AN) is disturbed eating behaviour [1]. Individuals with AN limit overall caloric intake and specifically calories derived from fat. This pattern of eating persists following weight recovery, and is associated with relapse in the longer term $[2,3]$. AN is a complex illness, and there are generalized neurocognitive deficits (e.g., set shifting, central coherence) [4, 5]. Yet, maladaptive eating behavior is central to the definition of $\mathrm{AN}$, leading to models and proposed neurobiological mechanisms of illness centered around aberrant brain responses to food [6]. Measures of neuropsychological processes, such as the Stroop task [7], have been adapted to include illness-specific words, which is thought to increase the attentional deficits among patients [8]. To understand maladaptive eating behaviour, experimental tasks have utilized images of food.

The primary purpose of this review is to identify and critically evaluate the food image tasks and paradigms that have been used in the study of AN. This systematic 
literature review identified neuropsychological, neurophysiological, and neuroimaging studies. Across these approaches, task domains included attention, reward, perception, and decision-making. While study findings are discussed, we primarily provide a qualitative review of the tasks themselves, and discuss how well these paradigms address phenomena central to AN.

\section{Methods}

\section{Search strategy and eligibility criteria}

PsychInfo and Medline were searched, using the search strategy shown in Fig. 1. Following deduplication, titles and abstracts were screened to determine whether the article should be included in the full-text screening stage. References in eligible studies were manually screened to identify studies not captured by database searches. Table 1 details inclusion criteria.

\section{Data Extraction, Synthesis, and Quality Assessment}

Participant details (age, AN subtype, BMI), task information (nature of task, observed variables) and study information (sample size, use of non-food control images, standardisation of pre-task intake, findings) were extracted. Studies were categorized by type (neuropsychology, neurophysiology, neuroimaging). The neuro psychology and neurophysiology tasks were further categorised by the following neurocognitive domains: attention, reward, perception, and decision-making. The qualitative review identified strengths and limitations of the tasks.

We used the Ferro and Speechley version [9] of the Downs and Black Quality Index [10] to provide a systematic assessment of study quality. A number of items were not applicable to the current review given the neurobiological nature of included studies. Consistent with an existing review [11], we removed the following items: response rate; estimates of the random variability; staff / places / facilities where patients studied representative; outcome measures valid and reliable. We also removed the confounding item given potential confounders varied substantially across studies. The final index consisted of 10 items; 10 was the maximum score (quality index item-level results available upon request).

\section{Results}

We identified 50 studies meeting eligibility criteria (Figure 2, PRISMA flow diagram). These studies are presented in Table 2.

\section{Neuropsychology Attention}

Attention directs sensory and cognitive processing, which in turn influences behaviour [12]. An attentional bias refers to the differential allocation of attention towards one set of stimuli over another. There are three components of attentional bias: increased capture of attention by a stimulus (orienting); reduced ability to direct attention away from a stimulus once attention has been captured (disengagement); and efforts to avoid allocating attention to a stimulus (attentional avoidance) [13]. Components of attentional bias have been studied in other areas of psychopathology, such as anxiety disorders. Individuals with anxiety disorders demonstrate an enhanced orienting towards "threat-related" stimuli, along with difficulties disengaging from such stimuli [13]. These biases are related to anxiety severity $[14,15]$. It has been hypothesised that individuals with AN might show similar attentional biases towards food stimuli, indicating a perceived threat, that might in turn be associated with greater dietary restriction [16]. On the other hand, attention to a food stimulus predicts consumption of that food (i.e., the opposite of dietary restriction [17])

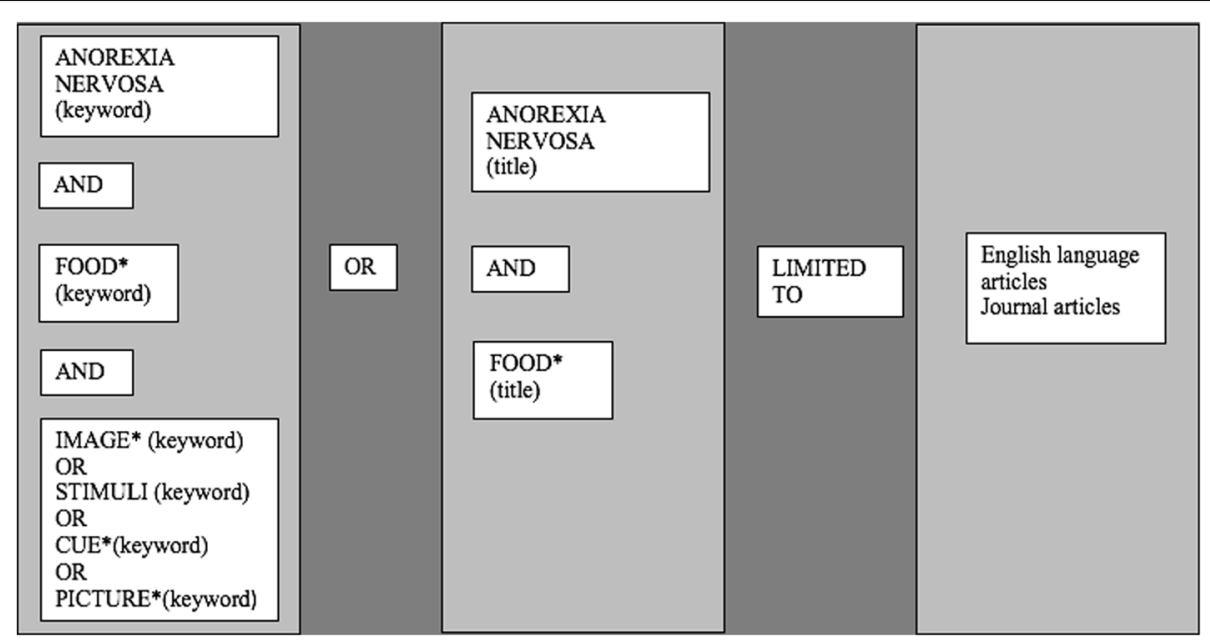

Fig. 1 Systematic Review Search Strategy 
Table 1 Systematic Review Inclusion Criteria

\begin{tabular}{|c|c|}
\hline $\begin{array}{l}\text { Sample } \\
\text { population }\end{array}$ & $\begin{array}{l}\text { Study included a defined group of individuals with AN or atypical AN (acutely ill or weight-restored). AN group was analysed separ } \\
\text { ately (i.e., studies with only mixed ED analyses were not included) }\end{array}$ \\
\hline Study design & Administration of a paradigm involving the presentation of real food images (i.e., not cartoons) \\
\hline Study type & Primary investigations only, secondary data analyses were not included \\
\hline $\begin{array}{l}\text { Outcome } \\
\text { measure }\end{array}$ & Any \\
\hline Date of study & Up to and including 10th March 2018 \\
\hline Publication type & Peer-reviewed full-text journal articles \\
\hline Language & English \\
\hline
\end{tabular}

in healthy individuals. As such, an alternative hypothesis is that individuals with AN would show reduced attentional bias towards food, and that this is a mechanism that facilitates dietary restriction [18]. Attention paradigms incorporating pictures of food have been administered to individuals with AN to test these competing hypotheses, to assess whether altered attention to food underlies maladaptive dietary restriction.

In distraction paradigms (Table 2, Distraction) pictures of food are presented while participants engage in an unrelated cognitive task. The difference in task performance when food images are presented as distractor items (as compared to neutral distractors) indicates an attentional bias. Individuals with AN were less accurate than healthy controls $(\mathrm{HC})$ in an attention task when distracted by food-related stimuli, with no group difference in the presence of neutral stimuli [18]. One study reported no differential effect of food versus other distractors on working memory accuracy among individuals with AN or HC [19]. However, another study reported working memory performance was compromised by food stimuli distractors among AN, but not $\mathrm{HC}$ [20]. In an inhibitory control task, food-image presentation was associated with decreased accuracy among $\mathrm{HC}$, but not AN [20].

In visual probe detection tasks [21, 22] participants identify the location of visual probes that replace food

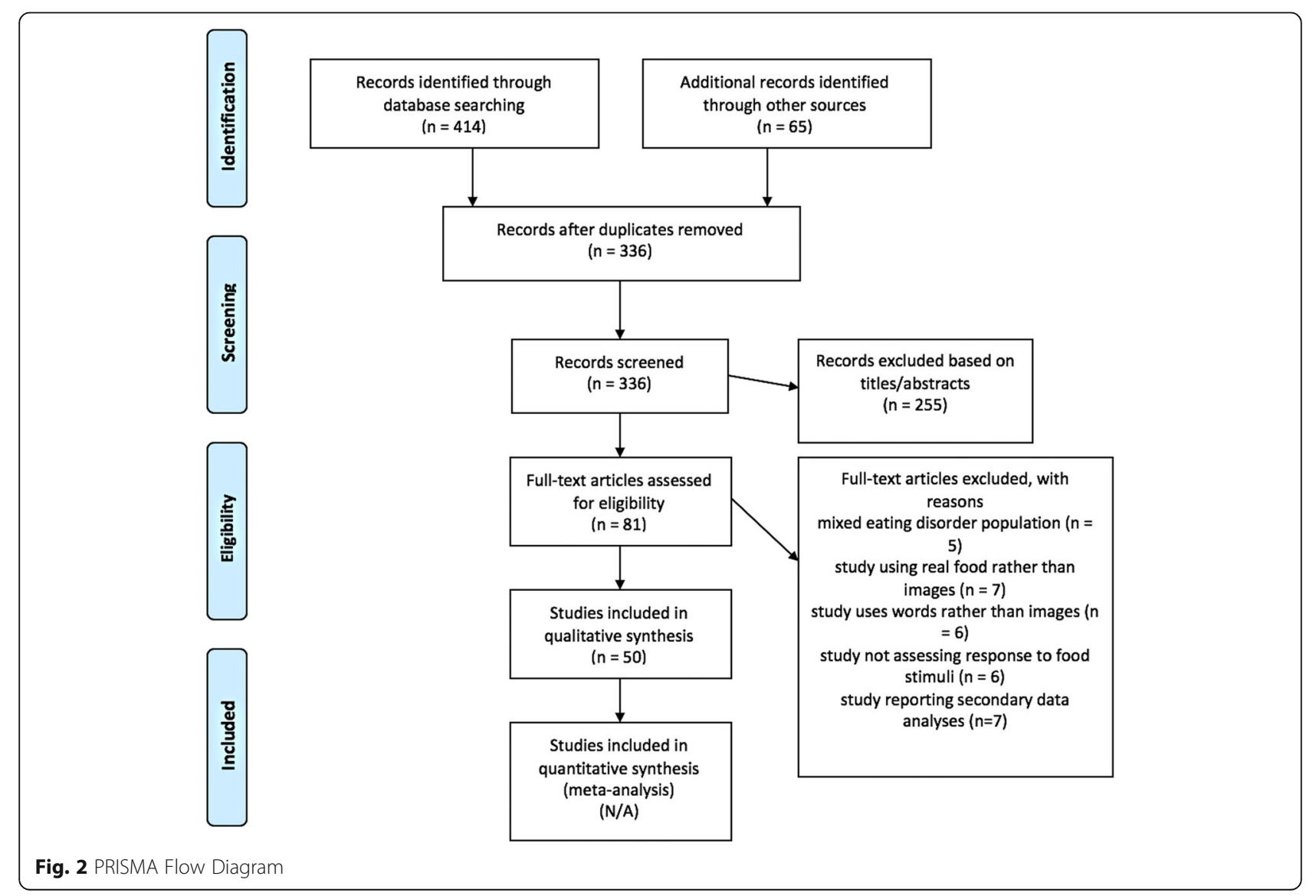




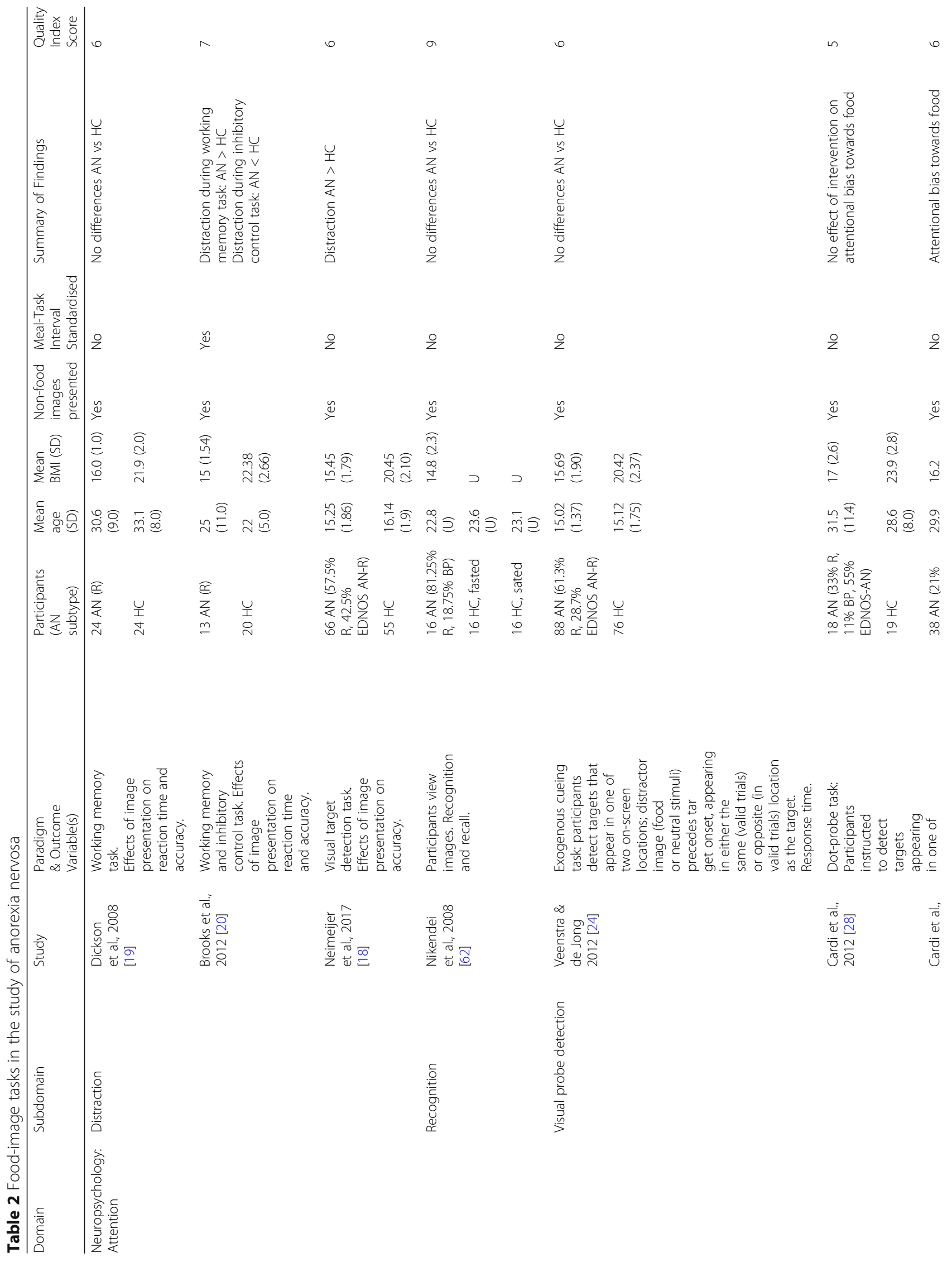




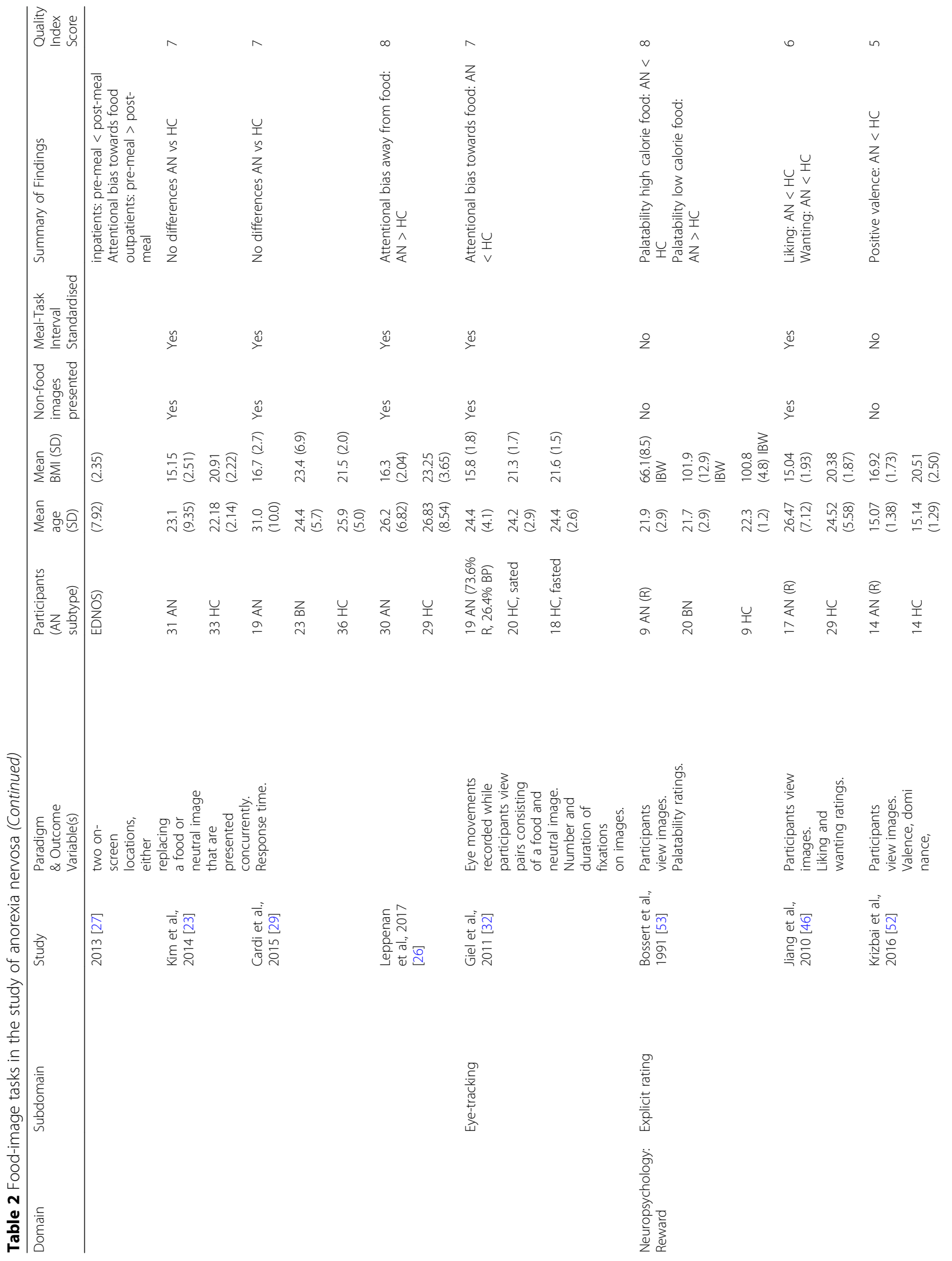




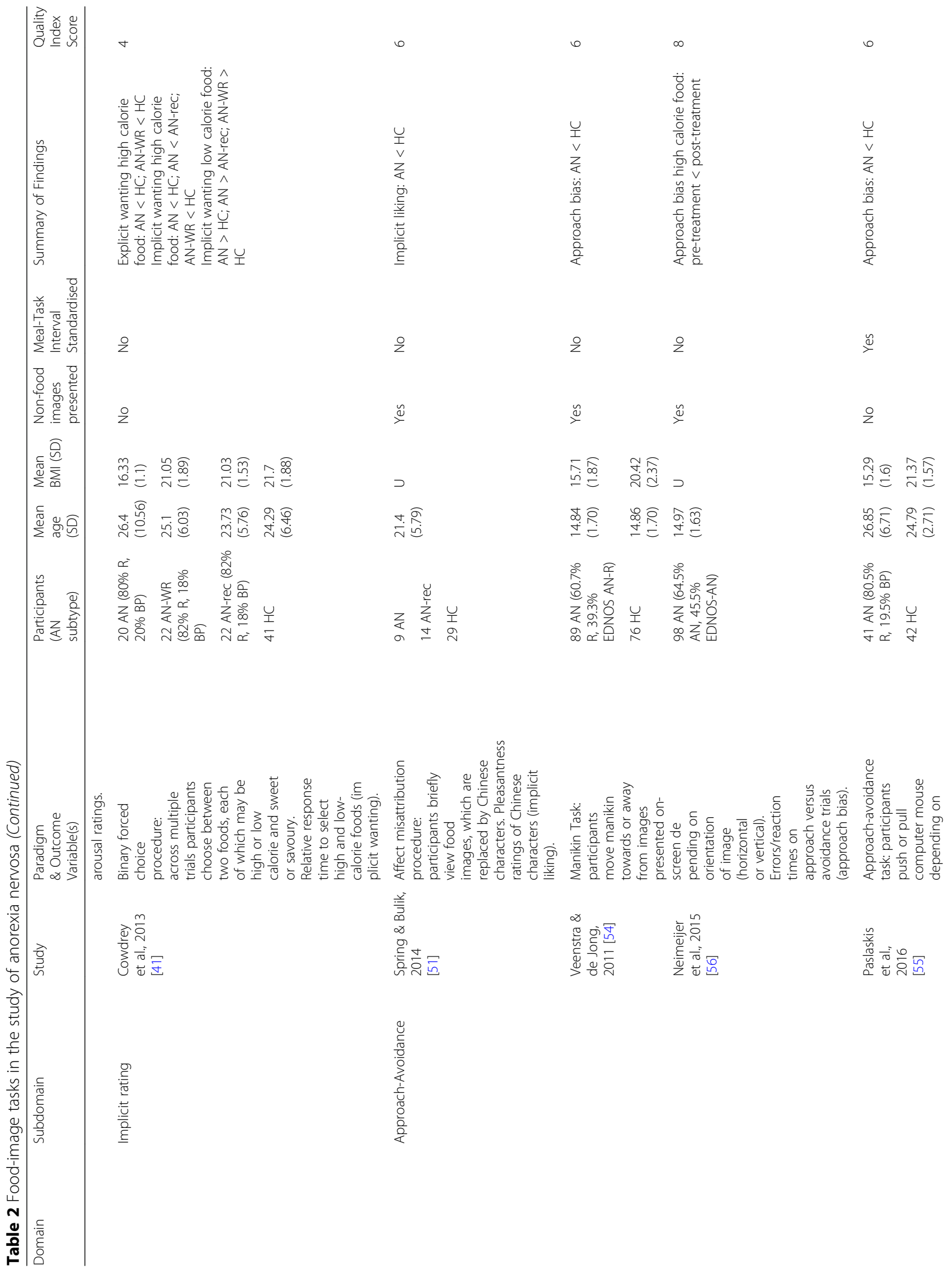




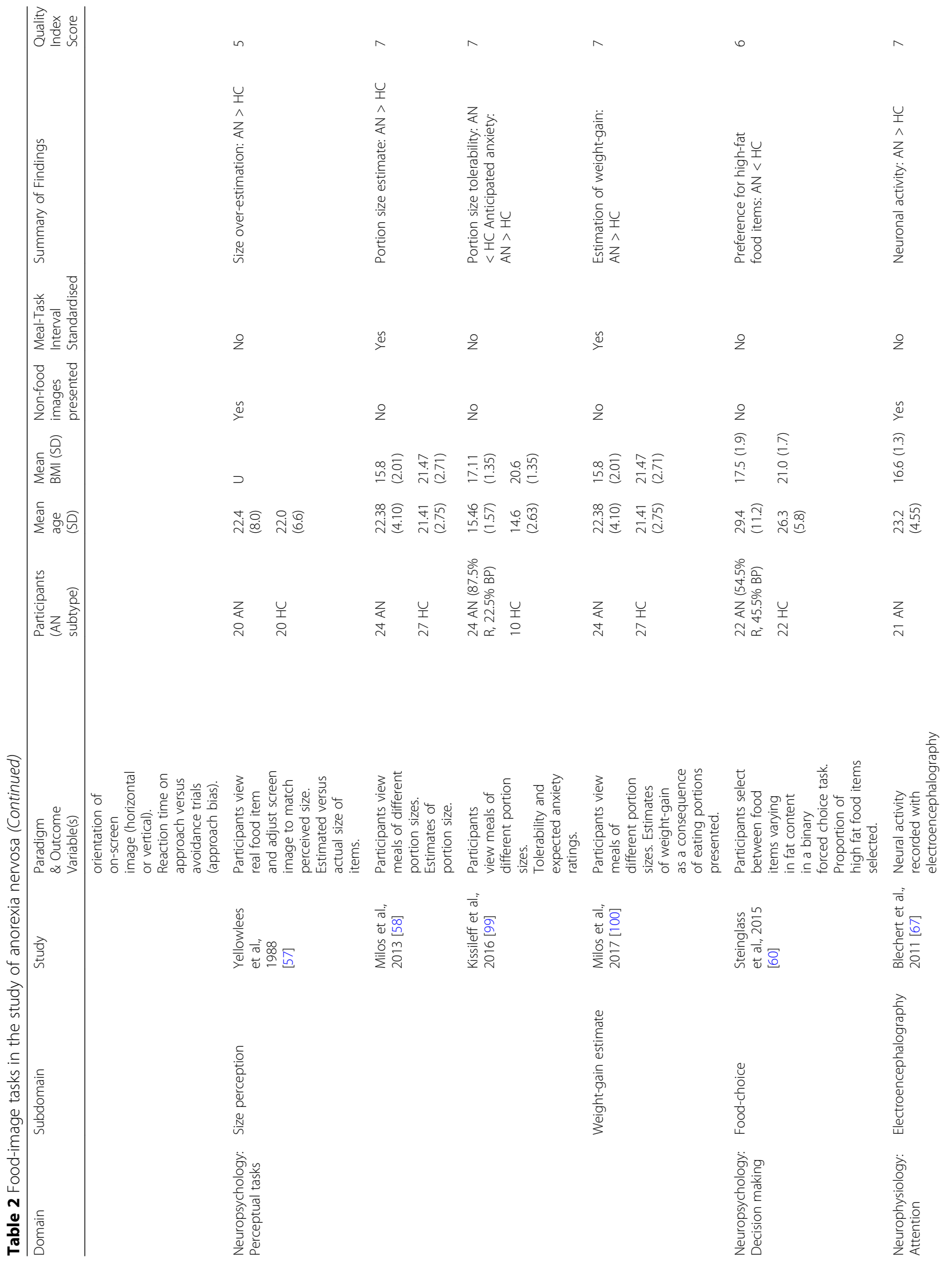




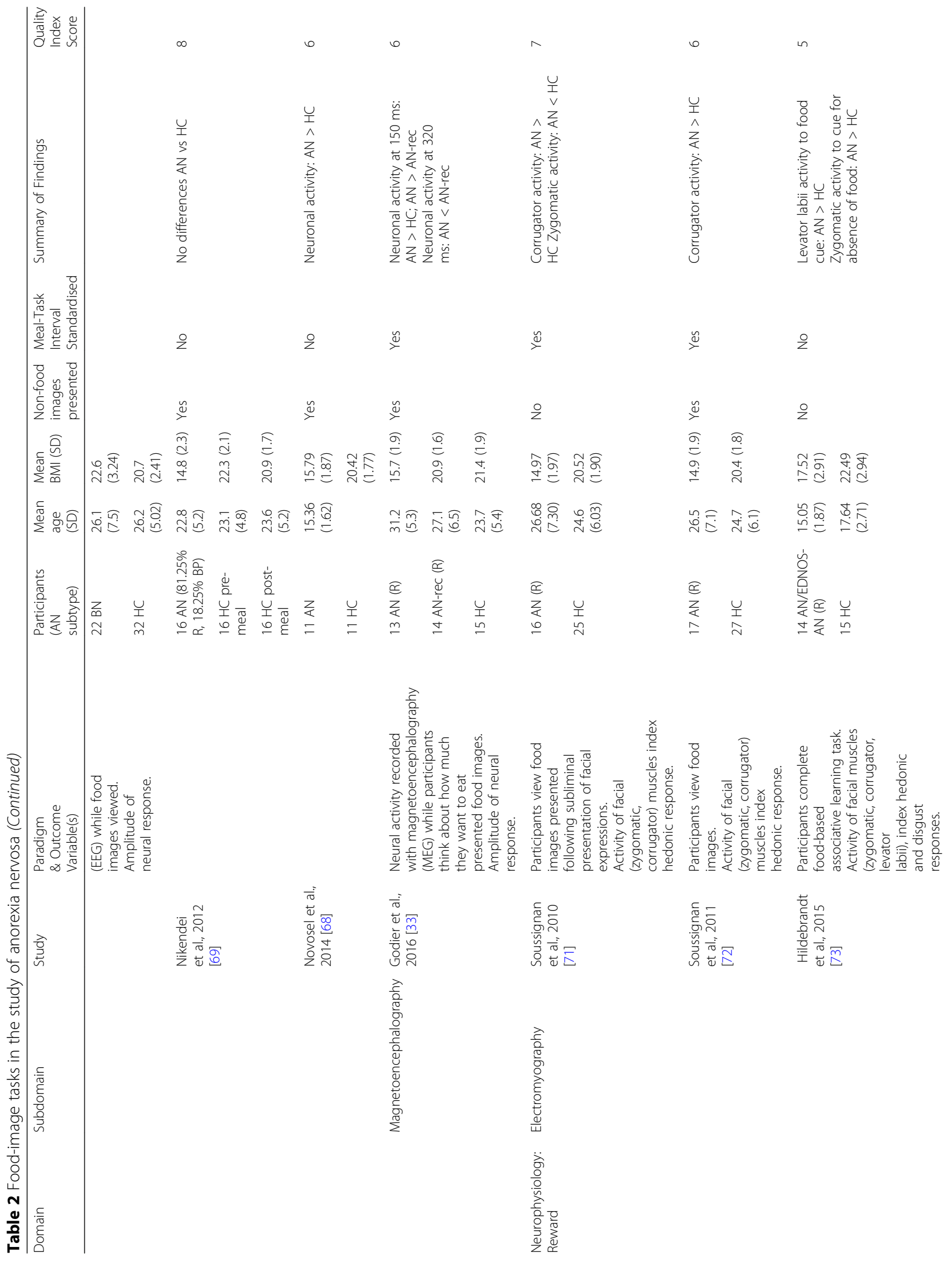




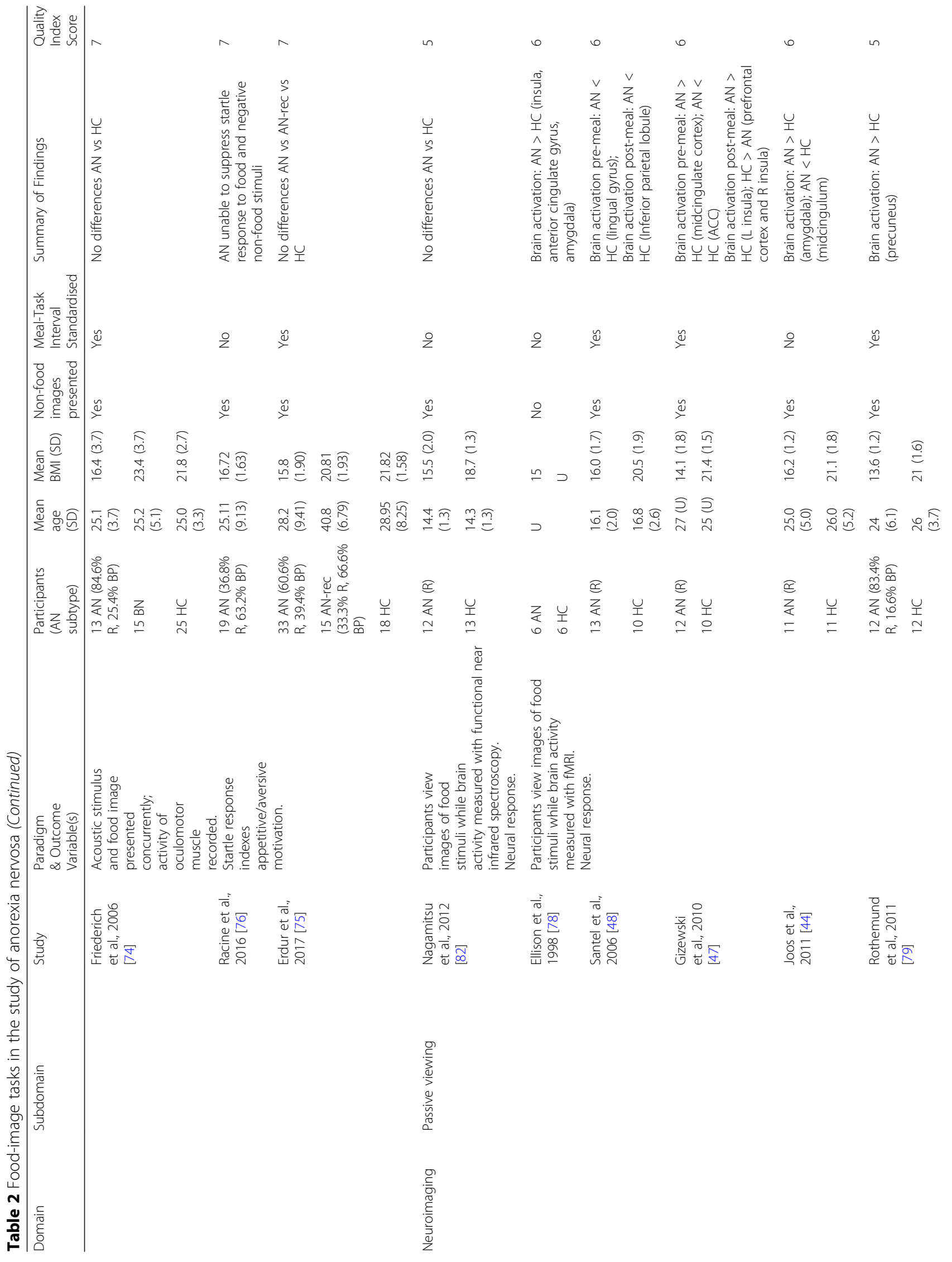




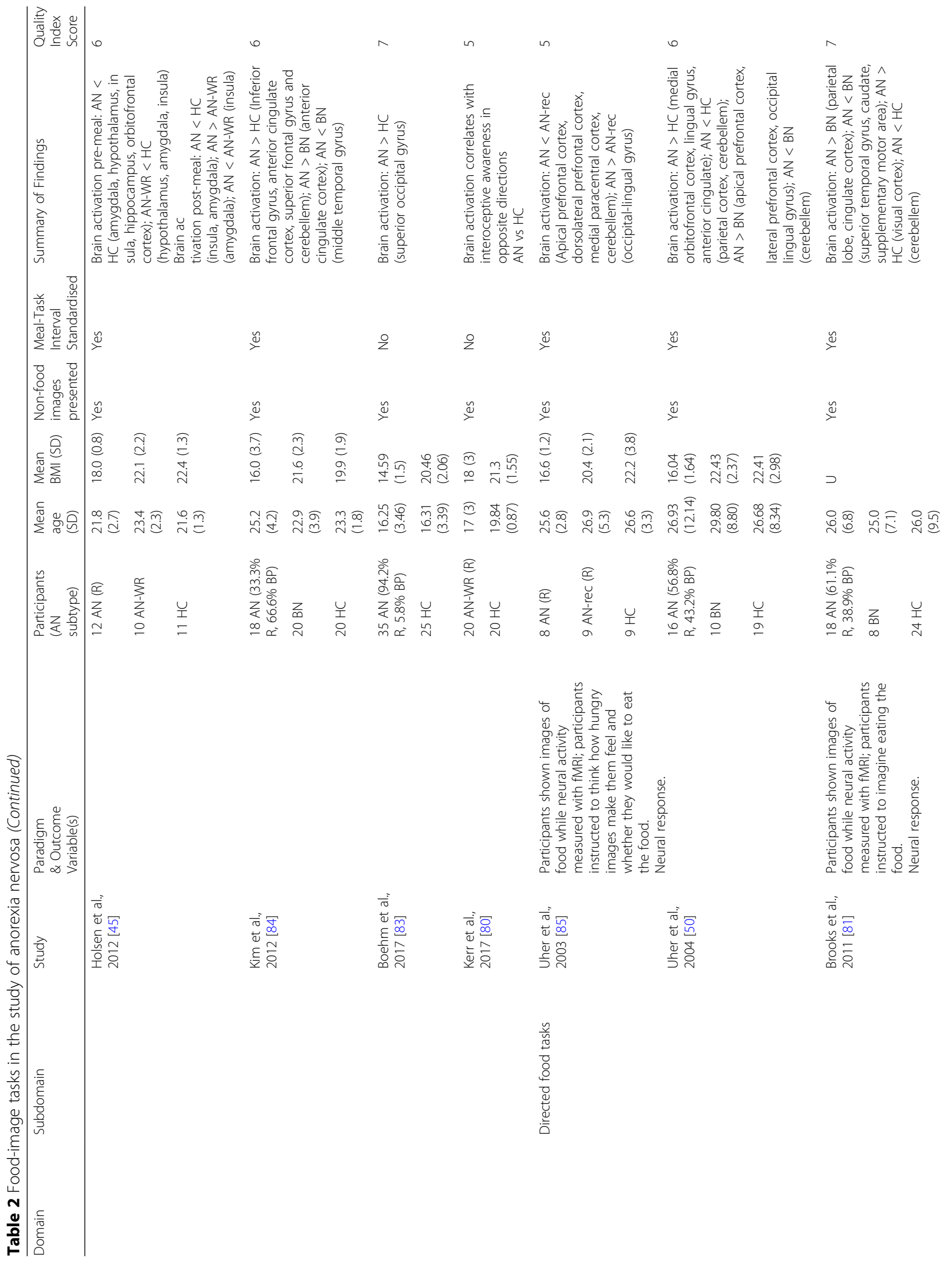




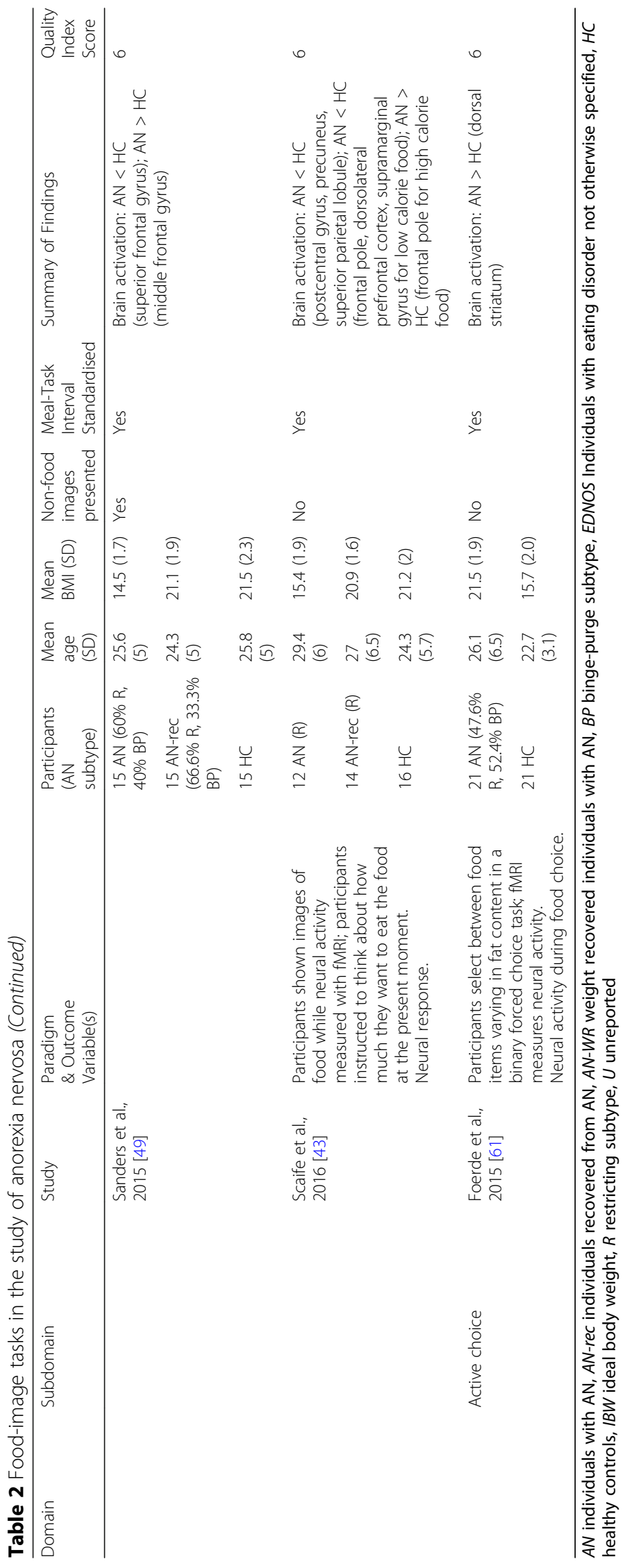


and non-food images (Table 2, Visual probe detection). Faster responses on food trials indicate greater attention to food stimuli (attentional bias towards food). Three studies found no evidence of differences between AN and $\mathrm{HC}$ in attentional bias towards food [23-25]. A fourth study found that when fasted, individuals with $\mathrm{AN}$, compared with $\mathrm{HC}$, displayed an attentional bias away from food stimuli [26]. Two studies of the effect of oxytocin $[23,26]$ and three of mealtime support interventions [27-29] explored whether attentional bias towards food mediated intervention effects on intake. Changes in attentional bias tended not to correspond with changes in food intake in AN, although small sample sizes limited detection of intervention effects in these studies.

Eye-tracking devices measure attention by monitoring the frequency and duration of gaze fixations at particular positions on a computer screen (Table 2, Eye-tracking $[30,31])$. One study found $\mathrm{AN}$ and $\mathrm{HC}$ did not differ in initial fixation points when high-calorie food and household items were presented concurrently, but the duration of fixations on food-images was shorter for individuals with AN [32]. When single images of food were presented, eye-gaze measurements did not differ between $\mathrm{AN}$ and $\mathrm{HC}$ [33].

There do not appear to be robust differences in attention bias to food between AN and $\mathrm{HC}$, though some studies of distraction suggest group differences. Interestingly, attention may be differentially associated with intake in the two populations.

\section{Reward}

Food is generally considered a primary reward [34], and therefore is useful for understanding how reward is assessed and processed. One approach to studying reward distinguishes separate components of liking and wanting [35, 36]. 'Liking' refers to the hedonic impact, or pleasure; 'wanting' refers to the motivation to consume a reward [37]. The rewarding properties of a food influence consumption among $\mathrm{HC}[38,39]$. This observation has resulted in the hypothesis that individuals with AN, who consume less food, do not experience food as rewarding [40], or that 'liking' or 'wanting' do not drive food consumption in the expected ways [41, 42]. To examine this, tasks have probed the reward value and processing of food by presenting images of food.

In the most straightforward behavioural paradigms, participants rate how pleasurable they find images of food, and/or how much they want to eat those foods (Table 2, Explicit rating task). Across multiple studies (behavioural and neuroimaging), individuals with AN report liking and wanting food less than $\mathrm{HC}$, especially high-calorie foods [33, 41, 43-53]. A variation of this task asks individuals to rate neutral images presented immediately after food stimuli (Table 2, Implicit rating task). Neutral images that follow food images are rated as less pleasant by AN than $\mathrm{HC}$ [51].

In forced-choice tasks, speed of response provides a behavioural index of motivation, separate from subjective ratings (Table 2, Binary forced choice task). For example, an individual may report not wanting to eat certain foods, but then respond rapidly to these foods during a task. This rapid response is thought to indicate an implicit 'wanting' that differs from the explicit rating. Across two studies, individuals with AN were slower than $\mathrm{HC}$ when selecting between two high-calorie foods [41, 43], and explicit wanting scores were also lower. In one study (but not the other) individuals with AN were faster than $\mathrm{HC}$ to select low-calorie foods [41]; this indication of greater implicit wanting was not reflected in the explicit response.

In approach-avoidance paradigms, participants are presented with images of food and neutral items, and instructed to either move toward (approach) or away from (avoid) the image, according to image orientation (i.e., portrait vs landscape). Approach-avoidance paradigms are based on the assumption that it is easier to approach than to avoid stimuli with motivational value. Error rates and response latencies on approach trials are subtracted from avoidance trials to calculate bias (positive values reflect an approach bias). Scores in the neutral condition are subtracted from the food condition, to calculate food-specific approach/avoidance bias. One study found that individuals with AN made fewer errors than $\mathrm{HC}$ on avoidance food trials, resulting in a reduced approach bias to food stimuli [54]. Another study found smaller differences in response times on food approach versus avoidance trials among individuals with $\mathrm{AN}$, also yielding a reduced approach bias in AN [55]. Adolescents with AN displayed an approach bias toward low-calorie, but not high-calorie, food stimuli before treatment [56]. After treatment, an approach bias was present for both types of food. These results are difficult to interpret in the absence of a $\mathrm{HC}$ group; one optimistic interpretation is that 'wanting' for high-calorie food increased with treatment.

The collection of findings from reward processing tasks suggest decreased value or reward of high-calorie food among individuals with AN, with mixed findings for low-calorie stimuli.

\section{Perception}

Individuals with AN often over-report caloric intake, despite under-consumption of food, raising a question about whether patients have a perceptual deficit. Some tasks test this idea by assessing perception of images of food and portion sizes (Table 2; Perceptual tasks). 
In one task, individuals adjust the size of images of food and neutral items presented on screen until these are perceived to match the size of actual items. Individuals with AN over-estimated food sizes relative to $\mathrm{HC}$, while estimates of neutral object size were similar between groups [57]. When presented with portions of food, individuals with AN overestimated the size of smaller (but not larger) portions [58]. Individuals with $\mathrm{AN}$, but not $\mathrm{HC}$, reported meal size to be larger when imagining they would eat the meal (intent to eat condition) compared to considering meal size "in general" (general condition).

These studies identified differences in assessments of portion size between $\mathrm{AN}$ and $\mathrm{HC}$, with no overall perceptual deficits.

\section{Decision-Making}

The only food-image decision-making task administered in AN measures food-choice, or, how individuals make decisions about what to eat $[59,60]$. In this task, participants rate a series of images of food for both healthiness and tastiness. One item that was rated neutral for both healthiness and tastiness is selected to be a "reference item" and participants then choose between the reference item and each of the other foods (Table 2, Decision-making). In studies of $\mathrm{AN}$, the main outcome is the proportion of trials in which the individual chooses a high-fat item over the reference item. Two studies have demonstrated that this task captures the decreased selection of high-fat foods by individuals with $\mathrm{AN}$, and task validity was additionally demonstrated by showing that proportion of high-fat choices correlated with actual caloric intake $[60,61]$. This task can be used to examine processes contributing to maladaptive dietary restriction in AN.

\section{Summary}

Quality Index scores were most commonly affected by methods of recruitment, where the checklist is very conservative. The checklist requires studies to report enrolment either of the entire population or of consecutive patients, and a description of the source of recruitment for healthy individuals. The studies we included often did not meet these criteria for reporting, but nonetheless generally enrolled reasonable samples of individuals with AN. Some studies that did include large sample sizes also included individuals who did not meet full criteria for $\mathrm{AN}$, which may limit the inferences that can be drawn $[18,24,56]$. Only one study included a power calculation [26]. Often sample sizes were small (e.g. [19, 52, $53,62])$. These factors were considered in the summary of findings.

Neuropsychological studies have captured differences in the cognitive appraisal of food in $\mathrm{AN}$, and these findings have informed theoretical models of AN. Specifically, findings from reward processing tasks support the hypothesis that abnormalities in neural reward systems underlie the development and maintenance of AN [7, 63]. Differences in attention towards food between AN and $\mathrm{HC}$ have not been consistent; whether attention relates to eating in $\mathrm{AN}$ is worthy of further investigation. Decision-making (food-choice) paradigms capture the characteristic eating behaviour of individuals with AN. These paradigms, if studied in connection with actual food intake, may yield insights into mechanisms of AN.

\section{Neurophysiology}

Physiological changes can index attitudes that are outside of conscious awareness [64]. Interest in measuring physiological responses to food in AN stems from clinical observations suggesting that individuals with $\mathrm{AN}$ may have difficulty describing symptoms and emotions.

\section{Attention}

Event related potentials (ERPs) are fluctuations in the brain's electrical activity, or electrical potentials, that are measured via scalp electrode electroencephalography (EEG). EEG has high temporal resolution, allowing for separation of ERPs into different components [65]. An ERP recording during stimulus presentation contains distinct components of early orienting and sustained attention [66]. Three studies measured ERPs during presentation of food images (Table 2, Event-related po tential). Two studies demonstrated that when food stimuli (but not neutral stimuli) were presented, individuals with AN initially display heightened ERP amplitudes compared to $\mathrm{HC}[67,68]$. At later stages of stimulus presentation, heightened ERP amplitudes in response to low-calorie foods in AN has been reported [68], although another study found no group difference in response to food versus non-food stimuli [69]. A related technique, magnetoencephalography (MEG), measures the electromagnetic field generated by the electrical activity of neurons, indexing brain activity also with high temporal resolution [70]. The one study using this technique reported heightened early activity in response to food stimuli in individuals with AN relative to $\mathrm{HC}$ [33].

\section{Reward}

Electromyography (EMG) tasks involve the recording of facial muscle contractions in response to images of food (Table 2, Electromyography). The amplitude of zygomatic (smiling) and corrugator (frowning) muscles are positively and negatively associated with pleasantness evaluations, respectively. When food images were presented following emotional primes (faces displaying happy, fear, disgust and neutral expressions) zygomatic responses to food images were decreased in individuals 
with AN, relative to $\mathrm{HC}$ [71]. A second study that included neutral stimuli found reduced zygomatic activity in AN versus $\mathrm{HC}$ for both types of images [72]. There was some indication of greater corrugator activity specifically in response to food stimuli in AN in both studies, but this varied with state (fasted or sated) and emotional priming. These studies also measured skin conductance and heart-rate changes; differences specific to food stimuli were not observed. The only EMG study of the levator labii muscle, associated with disgust, found activity increased among AN versus $\mathrm{HC}$ when participants viewed cues associated with chocolate [73]. This study also found increased zygomatic activity among AN in response to cues predicting the absence of chocolate. EMG has probed the startle eye-blink response to food, by measuring contraction of the orbicularis muscle that indexes aversion. Two studies found no startle-eye blink differences between $\mathrm{AN}$ and $\mathrm{HC}$ in response to food stimuli $[74,75]$. Another reported that individuals with AN had difficulties reducing their startle eye-blink responses towards food stimuli, as well as negative emotional stimuli, though there was no comparison group [76].

\section{Summary}

Quality Index scores were affected by the failure to fully report method of recruitment or failure to include exact p-values (e.g. [73]). Only one study was limited by the lack of a comparison group [76]; some studies had the added strength of comparing acutely ill patients with recovered individuals in addition to healthy individuals $[33,75]$. A selection of studies had the added rigor of either standardizing or controlling for states of feeding/ hunger [33, 69, 71, 72, 74, 75].

Neurophysiological approaches are less developed than neuropsychological, and may not have reached their full potential. ERP and MEG evidence suggest greater initial attention to food among individuals with AN, though sustained attention findings are inconsistent. EMG findings suggest a reduction in hedonic response to food. These physiological assessments provide another angle to examine neural mechanisms underlying responses to food.

\section{Neuroimaging (Functional Magnetic Resonance Imaging, fMRI)}

Neural correlates of illness have been examined using fMRI. One approach elicits psychiatric symptoms by presenting disorder-relevant stimuli, and measures associated neural activity (symptom provocation). Another method administers a task with known neural correlates to probe the functioning of the relevant brain system (cognitive activation probe; [77]). Food-image paradigms have been used to develop and test models of the neuropathology underlying AN.

\section{Passive Viewing of Food}

In passive viewing studies participants are asked to observe food stimuli during fMRI scanning (symptom provocation; Table 2, Passive viewing). Three studies reported altered amygdala activity among individuals with AN compared with HC $[44,45,78]$, and three studies reported altered insula activation $[45,47,78]$, however the direction of differences was not consistent between studies. Two studies reported alterations within visual processing areas in AN when high-calorie food was viewed, although exact loci and direction of difference was inconsistent $[48,79]$. One study did not find differences in neural activity between $\mathrm{AN}$ and $\mathrm{HC}$, but did report that neural activity during food-image viewing was differentially associated with stomach sensation ratings measured outside of the scanner in AN vs HC [80]. Collectively passive viewing studies have produced a diverse set of findings that are difficult to interpret.

\section{Directed Food Tasks}

To constrain the psychological experience when viewing food images (and in turn constrain the interpretation of findings), participants are given an instruction for how to internally process the images (symptom provocation, Table 2, Directed food tasks). When participants were asked to imagine eating presented foods, one study reported increased middle frontal gyrus activation in AN relative to $\mathrm{HC}$ [49], and another reported increased dorsolateral prefrontal cortex activity in AN [81]. When participants were asked to think about how hungry the presented foods made them, individuals with AN displayed greater ventromedial prefrontal cortex activity compared with $\mathrm{HC}$ [50]. When participants were instructed to think about how much they wished to eat each food item, increased frontal pole activity for high calorie foods was reported in AN but not HC [43]. A common finding amongst instructed viewing studies was altered frontal cortex activation in AN versus $\mathrm{HC}$, though specific regions differed.

\section{Active Food Choice}

The food choice task (described in Neuropsychology) $[60,61]$ provides a cognitive activation probe, in that it assesses active decision-making and the neural correlates in $\mathrm{HC}$ are known [59]. FMRI data showed that food choice was associated with dorsal striatum activity among individuals with AN, but not $\mathrm{HC}$ [61]. The dorsal striatum and dorsolateral prefrontal cortex were functionally correlated, and this connectivity was related to intake among individuals with AN. By linking the task with actual eating behaviour, this study provides 
compelling data that dorsal frontostriatal circuit activity is associated with the maladaptive food choices observed in $\mathrm{AN}$.

\section{Summary}

Quality Index scores were again affected by recruitment methods or descriptions (e.g. [79, 80, 82]). The majority of the studies involved very small numbers of participants, by current standards for fMRI investigations. Conclusions may be more robust for investigations with sample sizes greater than 20 per group (e.g. [61, 80, 83]). Some studies have the additional methodological strength of standardizing time since meals [43, 45, 47$50,61,79,81,84,85]$, and of including non-food stimulus comparisons [44, 45, 47-50, 79-85].

Neuroimaging studies involving passive viewing of food have not identified consistent group differences. Adding an instruction for viewing has identified differences in frontal regions, in varying locations. Neural regions have multiple functions; various different processes may be captured during the viewing of food stimuli (even with instructions), making it difficult to draw inferences about mechanisms of illness from these paradigms. The only approach that linked neural activity with eating behaviour identified dorsal frontostriatal circuit engagement in AN. This is a promising finding that, if replicated, can open new avenues for research [86].

\section{Discussion}

Tasks using images of food have been administered in 50 different studies of AN, using neuropsychological, neurophysiological, and neuroimaging techniques. This systematic review primarily assessed the utility of the experimental approaches. Nonetheless, some conclusions can be drawn from the data. First, while attention is related to intake among healthy individuals [17], data from four studies suggest that attention and eating behaviour are dissociated among individuals with AN [23, 25-27]. While a small collection of neurophysiological evidence suggests greater attentional orienting towards food stimuli in AN as compared to $\mathrm{HC}$, findings from neuropsychological studies of attention are inconsistent. Second, measures of liking, value, and choice from neuropsychological and neurophysiological studies converge to indicate that individuals with $\mathrm{AN}$ have a decreased preference for high-fat/calorie foods. Third, while it is one study, the only data that linked maladaptive eating with neuroimaging indicated that this behaviour is associated with dorsal frontostriatal activity [61] .

The paradigms and approaches that have been used to date have some notable strengths, as well as important weaknesses. The strengths of the neuropsychological tasks are that they have probed constructs of interest, and some have well characterized underlying neural mechanisms. For example, wanting and liking tasks have been associated with mesolimbic activity among $\mathrm{HC}$, suggesting they probe reward systems [87, 88]. The strengths of the neurophysiological measures include the objectivity of the assessment, as well as temporal resolution that offers a granular study of cognitive processes (i.e., assessing components of broad cognitive processes) $[65,89]$. Neuroimaging methods do not have the same temporal resolution, but do have spatial resolution that enables identification of relevant brain regions [90]. Development of paradigms within these fields may allow the parsing of distinct neurocognitive processes and circuits, for an understanding of their role in AN.

The majority of studies involved small sample sizes and specific populations that limit generalizability. The studies ranged in quality, as assessed by the checklist. While this index is the most appropriate available, it is not specifically designed for cognitive neuroscience studies and so the index score does not address the specificity of the data collected. For example, neuropsychological tasks engage multiple neurocognitive domains, even when one variable is identified as the primary outcome. Techniques like EMG and EEG have limited spatial resolution, making neurologic interpretation difficult $[65,91]$. FMRI data also captures multiple processes - particularly when responses are not constrained. It is a limitation of this systematic review that the assessment of each paradigm may be influenced by the quality of the study.

The major limitation across paradigms has been the absence of information about the relationship between task variables and eating behaviour among individuals with AN. One interesting dilemma in this research is how best to utilize cognitive neuroscience when the behaviour of interest differs between groups. That is, for many of these tasks, the association between task variables and eating behaviour has been established in $\mathrm{HC}$, but this relationship is not present in AN. For example, 'liking' and 'wanting' are associated with actual eating among individuals without an eating disorder [87, 88], and attention is associated with food intake among $\mathrm{HC}$ [17]. Yet, the association between attention and intake is not so clear in AN, as shown in the studies reviewed here. On the one hand, it is interesting and potentially important to learn that these processes are dissociated in AN. On the other hand, interpreting the finding requires additional information about the relationship between attention and the maladaptive eating behaviour characteristic of AN.

Approaches used to study eating behaviour in populations of individuals without an eating disorder may offer new ideas that can enhance the utility of existing tasks in AN. By studying the effects of experimental manipulations on food choice, causal influences on eating 
behaviour have been identified in healthy individuals. For example, the role of attention to particular characteristics of food was assessed by asking participants to focus specifically on one value (tastiness or healthiness) of presented foods when making choices. Receiving the instruction to focus on healthiness increased the influence of healthiness on decisions. FMRI data showed that the change in preference was associated with greater functional connectivity between the dorsolateral and ventromedial prefrontal cortices [92]. This cognitive manipulation may be useful in understanding decisionmaking processes in AN, again highlighting the utility of food choice paradigms.

In motor approach training, participants learn to press a button in response to particular food images presented on-screen. The comparison of food value ratings made before and after the training demonstrated that the approach training increased the reward value of the associated foods and increased choice of these foods [93]. On the flip side, with motor inhibition training individuals learn to inhibit or withhold automatic approach responses to food stimuli. Among overweight and obese participants, this resulted in decreased liking of high-calorie foods, reduced neural activity in reward-signalling regions in response to high-calorie foods, and reduced caloric intake [94-97]. Motor approach or inhibition may be useful in AN, as well, where changing value assessment and choice of foods may be therapeutic [98].

Three ideas emerge from this review that may advance research. One, the link between experimental measurements and the eating behaviour characteristic of AN is critical to establishing mechanisms of illness. Two, introducing experimental manipulations may allow for inferences about causality. Neuroimaging in conjunction with manipulations may further elucidate the neural underpinnings of maladaptive eating. Three, perhaps most importantly, clear hypotheses should guide the selection of tasks and approaches, so that research questions may be fully addressed, and in a reliable and valid manner. Much of the food-image research to date has been descriptive; it is time to begin testing the mechanistic hypotheses that have emerged.

\section{Abbreviations}

AN: Anorexia nervosa; EEG: Electroencephalography; EMG: Electromyography; ERP: Event-related potential; FMRI: Functional magnetic resonance imaging; MEG: Magnetoencephalography; HC: Healthy controls

\section{Acknowledgements}

The authors would like to thank Anne Haase and Jeff Brunstrom for reviewing the article prior to journal submission.

\section{Funding}

E.C.L. is supported by an Economic and Social Research Council [ESRC] Studentship award. J.E.S. is supported by the New York State Office of Mental Health.
Availability of data and materials

Not applicable

\section{Authors' contributions}

E.C.L.: literature review; interpretation of existing research findings; article drafting. J.E.S.: conception and design of the review; interpretation of existing research findings; critical revision of the article. Both authors read and approved the final manuscript.

Ethics approval and consent to participate

Not applicable

\section{Consent for publication}

Not applicable

\section{Competing interests}

J.E.S. receives royalties from Up To Date.

\section{Publisher's Note}

Springer Nature remains neutral with regard to jurisdictional claims in published maps and institutional affiliations.

\section{Author details}

${ }^{1}$ Centre for Exercise, Nutrition and Health Sciences, School for Policy Studies, University of Bristol, Bristol, UK. ${ }^{2}$ Department of Psychiatry, Columbia University Irving Medical Center, New York, NY, USA. ${ }^{3}$ New York State Psychiatric Institute, New York, NY, USA.

Received: 15 December 2017 Accepted: 11 September 2018

Published online: 01 November 2018

\section{References}

1. Walsh BT. The importance of eating behavior in eating disorders. Physiol Behav. 2011;104(4):525-9.

2. Schebendach JE, Mayer LE, Devlin MJ, Attia E, Contento IR, Wolf RL, Walsh BT. Dietary energy density and diet variety as predictors of outcome in anorexia nervosa. Am J Clin Nutr. 2008;87(4):810-6.

3. Schebendach J, Mayer LE, Devlin MJ, Attia E, Walsh BT. Dietary energy density and diet variety as risk factors for relapse in anorexia nervosa: a replication. Int J Eat Disord. 2012;45(1):79-84.

4. Lang K, Roberts M, Harrison A, Lopez C, Goddard E, Khondoker M, et al. Central Coherence in Eating Disorders: A Synthesis of Studies Using the Rey Osterrieth Complex Figure Test. PLOS ONE. 2016;11(11):e0165467.

5. Roberts ME, Tchanturia K, Stahl D, Southgate L, Treasure J. A systematic review and meta-analysis of set-shifting ability in eating disorders. 2007; 37(8):1075-1084.

6. Park RJ, Godier LR, Cowdrey FA. Hungry for reward: How can neuroscience inform the development of treatment for Anorexia Nervosa? Behav Res Ther. 2014;62:47-59.

7. Stroop JR. Studies of interference in serial verbal reactions. Journal of experimental psychology. 1935;18(6):643.

8. Aspen V, Darcy AM, Lock J. A review of attention biases in women with eating disorders. Cognit Emot. 2013;27(5):820-38.

9. Ferro MA, Speechley KN. Depressive symptoms among mothers of children with epilepsy: a review of prevalence, associated factors, and impact on children. Epilepsia. 2009;50(11):2344-54.

10. Downs SH, Black N. The feasibility of creating a checklist for the assessment of the methodological quality both of randomised and non-randomised studies of health care interventions. J Epidemiol Community Health. 1998;52(6):377.

11. Donnelly B, Touyz S, Hay P, Burton A, Russell J, Caterson I. Neuroimaging in bulimia nervosa and binge eating disorder: a systematic review. J Eat Disord. 2018;6:3

12. Driver J. A selective review of selective attention research from the past century. Br J Psychol. 2001;92(Pt 1):53-78.

13. Cisler JM, Koster EH. Mechanisms of attentional biases towards threat in anxiety disorders: An integrative review. Clin Psychol Rev. 2010;30(2):203-16.

14. Van Bockstaele B, Verschuere B, Tibboel H, De Houwer J, Crombez G, Koster $\mathrm{EH}$. A review of current evidence for the causal impact of attentional bias on fear and anxiety. Psychol Bull. 2014;140(3):682-721.

15. Price RB, Wallace M, Kuckertz JM, Amir N, Graur S, Cummings L, et al. Pooled patient-level meta-analysis of children and adults completing a 
computer-based anxiety intervention targeting attentional bias. Clin Psychol Rev. 2016;50:37-49.

16. Cowdrey FA, Park RJ, Harmer CJ, McCabe C. Increased neural processing of rewarding and aversive food stimuli in recovered anorexia nervosa. Biol Psychiatry. 2011;70(8):736-43.

17. Werthmann J, Jansen A, Roefs A. Worry or craving? A selective review of evidence for food-related attention biases in obese individuals, eatingdisorder patients, restrained eaters and healthy samples. Proc Nutr Soc. 2015;74(2):99-114.

18. Neimeijer RAM, Roefs A, de Jong PJ. Heightened Attentional Capture by Visual Food Stimuli in Anorexia Nervosa. J Abnorm Psychol. 2017;126(6):805-811.

19. Dickson H, Brooks S, Uher R, Tchanturia K, Treasure J, Campbell IC. The inability to ignore: Distractibility in women with restricting anorexia nervosa. Psychol Med. 2008;38(12):1741-8.

20. Brooks SJ, O'Daly OG, Uher R, Schiöth HB, Treasure J, Campbell IC. Subliminal food images compromise superior working memory performance in women with restricting anorexia nervosa. Conscious Cogn. 2012;21(2):751-63.

21. MacLeod C, Mathews A, Tata P. Attentional bias in emotional disorders. J Abnorm Psychol. 1986;95(1):15-20.

22. Posner MI, Snyder CR, Davidson BJ. Attention and the detection of signals. J Exp Psychol. 1980;109(2):160-74.

23. Kim YR, Kim CH, Cardi V, Eom JS, Seong Y, Treasure J. Intranasal oxytocin attenuates attentional bias for eating and fat shape stimuli in patients with anorexia nervosa. Psychoneuroendocrinology. 2014;44:133-42.

24. Veenstra EM, de Jong PJ. Attentional bias in restrictive eating disorders. Stronger attentional avoidance of high-fat food compared to healthy controls? Appetite. 2012;58(1):133-40.

25. Cardi V, Esposito M, Clarke A, Schifano S, Treasure J. The impact of induced positive mood on symptomatic behaviour in eating disorders. An experimental, $\mathrm{AB} / \mathrm{BA}$ crossover design testing a multimodal presentation during a test-meal. Appetite. 2015;87:192-8.

26. Leppanen J, Cardi V, Ng KW, Paloyelis Y, Stein D, Tchanturia K, Treasure J. The effects of intranasal oxytocin on smoothie intake, cortisol and attentional bias in anorexia nervosa. Psychoneuroendocrinology. 2017;79:167-74.

27. Cardi V, Lounes N, Kan C, Treasure J. Meal support using mobile technology in Anorexia Nervosa. Contextual differences between inpatient and outpatient settings. Appetite. 2013;60(1):33-9.

28. Cardi V, Kan C, Roncero M, Harrison A, Lounes N, Tchanturia K, et al. Mealtime Support in Anorexia Nervosa: A Within-Subject Comparison Study of a Novel Vodcast Intervention. Psychotherapy and Psychosomatics. 2012; 81(1):54-5.

29. Cardi V, Leppanen J, Treasure J. The effects of negative and positive mood induction on eating behaviour: A meta-analysis of laboratory studies in the healthy population and eating and weight disorders. Neurosci Biobehav Rev. 2015;57:299-309.

30. Duc AH, Bays P, Husain M. Eye movements as a probe of attention. Prog Brain Res. 2008;171:403-11.

31. Jiang MY, Vartanian LR. A review of existing measures of attentional biases in body image and eating disorders research. Australian Journal of Psychology. 2018;70(1):3-17.

32. Giel KE, Friederich HC, Teufel M, Hautzinger M, Enck P, Zipfel S. Attentional processing of food pictures in individuals with anorexia nervosa--an eyetracking study. Biol Psychiatry. 2011;69(7):661-7.

33. Godier LR, Scaife JC, Braeutigam S, Park RJ. Enhanced Early Neuronal Processing of Food Pictures in Anorexia Nervosa: A Magnetoencephalography Study. Psychiatry J. 2016;2016:1795901.

34. Skinner BF. Science and human behavior: Simon and Schuster; 1953

35. Berridge KC. Food reward: Brain substrates of wanting and liking. Neurosci Biobehav Rev. 1996;20(1):1-25.

36. Robinson TE, Berridge KC. The neural basis of drug craving: an incentive-sensitization theory of addiction. Brain Res Brain Res Rev. 1993;18(3):247-91

37. Berridge KC, Robinson TE, Aldridge JW. Dissecting components of reward: 'liking', 'wanting', and learning. Curr Opin Pharmacol. 2009;9(1):65-73.

38. Rogers PJ, Hardman CA. Food reward. What it is and how to measure it. Appetite. 2015;90:1-15.

39. De Graaf C, De Jong LS, Lambers AC. Palatability Affects Satiation But Not Satiety. Physiol Behav. 1999;66(4):681-8.

40. Davis C, Woodside DB. Sensitivity to the rewarding effects of food and exercise in the eating disorders. Compr Psychiatry. 2002;43(3):189-94.
41. Cowdrey FA, Finlayson G, Park RJ. Liking compared with wanting for highand low-calorie foods in anorexia nervosa: aberrant food reward even after weight restoration. Am J Clin Nutr. 2013;97(3):463-70.

42. Berridge KC. 'Liking' and 'wanting' food rewards: brain substrates and roles in eating disorders. Physiol Behav. 2009;97(5):537-50.

43. Scaife JC, Godier LR, Reinecke A, Harmer CJ, Park RJ. Differential activation of the frontal pole to high vs low calorie foods: The neural basis of food preference in Anorexia Nervosa? Psychiatry Res. 2016;258: 44-53.

44. Joos AA, Saum B, van Elst LT, Perlov E, Glauche V, Hartmann A, et al. Amygdala hyperreactivity in restrictive anorexia nervosa. Psychiatry Res. 2011;191(3):189-95.

45. Holsen LM, Lawson EA, Blum J, Ko E, Makris N, Fazeli PK, et al. Food motivation circuitry hypoactivation related to hedonic and nonhedonic aspects of hunger and satiety in women with active anorexia nervosa and weight-restored women with anorexia nervosa. J Psychiatry Neurosci. 2012:37(5):322-32.

46. Jiang T, Soussignan R, Rigaud D, Schaal B. Pleasure for visual and olfactory stimuli evoking energy-dense foods is decreased in anorexia nervosa. Psychiatry Res. 2010;180(1):42-7.

47. Gizewski ER, Rosenberger C, de Greiff A, Moll A, Senf W, Wanke I, et al. Influence of satiety and subjective valence rating on cerebral activation patterns in response to visual stimulation with high-calorie stimuli among restrictive anorectic and control women. Neuropsychobiology. 2010;62(3):182-92.

48. Santel S, Baving L, Krauel K, Münte TF, Rotte M. Hunger and satiety in anorexia nervosa: fMRI during cognitive processing of food pictures. Brain Res. 2006;1114(1):138-48.

49. Sanders N, Smeets PA, van Elburg AA, Danner UN, van Meer F, Hoek HW, Adan RA. Altered food-cue processing in chronically ill and recovered women with anorexia nervosa. Front Behav Neurosci. 2015;9:46.

50. Uher R, Murphy T, Brammer MJ, Dalgleish T, Phillips ML, Ng WW, et al. Medial prefrontal cortex activity associated with symptom provocation in eating disorders. Am J Psychiatry. 2004;161(7):1238-46.

51. Spring VL, Bulik CM. Implicit and explicit affect toward food and weight stimuli in anorexia nervosa. Eat Behav. 2014;15(1):91-4.

52. Krizbai T, Csenki L, Paszthy B, Szabo P. Emotional and autobiographical memory deficits in Anorexia Nervosa. J Evid Based Psychotherapies. 2016; 16(2):191-204.

53. Bossert S, Laessle RG, Meiller C, Junker M, Ellgring H, Pirke KM. Visual palatability of food in patients with eating disorders and dieting women. Behav Res Ther. 1991;29(4):337-41.

54. Veenstra EM, de Jong PJ. Reduced automatic motivational orientation towards food in restricting anorexia nervosa. J Abnorm Psychol. 2011; 120(3):708-18.

55. Paslakis G, Kühn S, Schaubschläger A, Schieber K, Röder K, Rauh E, Erim Y. Explicit and implicit approach vs. avoidance tendencies towards high vs. low calorie food cues in patients with anorexia nervosa and healthy controls. Appetite. 2016;107:171-9.

56. Neimeijer RA, de Jong PJ, Roefs A. Automatic approach/avoidance tendencies towards food and the course of anorexia nervosa. Appetite. 2015;91:28-34.

57. Yellowlees PM, Roe M, Walker MK, Ben-Tovim DI. Abnormal perception of food size in anorexia nervosa. Br Med J Clin Res Ed. 1988;296(6638): 1689-90.

58. Milos G, Kuenzli C, Soelch CM, Schumacher S, Moergeli H, Mueller-Pfeiffer C. How much should I eat? Estimation of meal portions in anorexia nervosa. Appetite. 2013;63:42-7.

59. Hare TA, Camerer CF, Rangel A. Self-control in decision-making involves modulation of the vmPFC valuation system. Science. 2009;324(5927):646-8.

60. Steinglass J, Foerde K, Kostro K, Shohamy D, Timothy Walsh B. Restrictive Food Intake As A Choice - A Paradigm for Study. Int J Eat Disord. 2015;48(1):59-66.

61. Foerde K, Steinglass JE, Shohamy D, Walsh BT. Neural mechanisms supporting maladaptive food choices in anorexia nervosa. Nat Neurosci. 2015;18(11):1571-3.

62. Nikendei C, Weisbrod M, Schild S, Bender S, Walther S, Herzog W, et al. Anorexia nervosa: Selective processing of food-related word and pictorial stimuli in recognition and free recall tests. Int J Eat Disord. 2008;41(5):439-47.

63. Kaye $W H$, Fudge $J$, Paulus M. New insights into symptoms and neurocircuit function of anorexia nervosa. Nat Rev Neurosci. 2009;10(8):573-84. 
64. Pool E, Sennwald V, Delplanque S, Brosch T, Sander D. Measuring wanting and liking from animals to humans: A systematic review. Neurosci Biobehav Rev. 2016;63:124-42.

65. Luck SJ. An introduction to the event-related potential technique. Cambridge: MIT press; 2014

66. Hillyard SA, Anllo-Vento L. Event-related brain potentials in the study of visual selective attention. Proc Natl Acad Sci. 1998;95(3):781.

67. Blechert J, Feige B, Joos A, Zeeck A, Tuschen-Caffier B. Electrocortical processing of food and emotional pictures in anorexia nervosa and bulimia nervosa. Psychosom Med. 2011;73(5):415-21.

68. Novosel A, Lackner N, Unterrainer HF, Dunitz-Scheer M, Scheer PJ, WallnerLiebmann SJ, Neuper C. Motivational processing of food cues in anorexia nervosa: a pilot study. Eat Weight Disord. 2014;19(2):169-75.

69. Nikendei C, Friederich HC, Weisbrod M, Walther S, Sharma A, Herzog W, et al. Event-related potentials during recognition of semantic and pictorial food stimuli in patients with anorexia nervosa and healthy controls with varying internal states of hunger. Psychosom Med. 2012;74(2):136-45.

70. Baillet S. Magnetoencephalography for brain electrophysiology and imaging. Nat Neurosci. 2017;20(3):327-39.

71. Soussignan R, Jiang T, Rigaud D, Royet JP, Schaal B. Subliminal fear priming potentiates negative facial reactions to food pictures in women with anorexia nervosa. Psychol Med. 2010;40(3):503-14.

72. Soussignan R, Schaal B, Rigaud D, Royet JP, Jiang T. Hedonic reactivity to visual and olfactory cues: rapid facial electromyographic reactions are altered in anorexia nervosa. Biol Psychol. 2011;86(3):265-72.

73. Hildebrandt T, Grotzinger A, Reddan M, Greif R, Levy I, Goodman W, Schiller D. Testing the disgust conditioning theory of food-avoidance in adolescents with recent onset anorexia nervosa. Behav Res Ther. 2015;71:131-8.

74. Friederich HC, Kumari V, Uher R, Riga M, Schmidt U, Campbell IC, et al. Differential motivational responses to food and pleasurable cues in anorexia and bulimia nervosa: a startle reflex paradigm. Psychol Med. 2006;36(9):1327-35.

75. Erdur L, Weber C, Zimmermann-Viehoff F, Rose M, Deter HC. Affective Responses in Different Stages of Anorexia Nervosa: Results from a Startlereflex Paradigm. Eur Eat Disord Rev. 2017;25(2):114-22.

76. Racine SE, Forbush KT, Wildes JE, Hagan KE, Pollack LO, May C. Voluntary emotion regulation in anorexia nervosa: A preliminary emotion-modulated startle investigation. J Psychiatr Res. 2016;77:1-7.

77. Breiter HC, Rauch SL. Functional MRI and the study of OCD: from symptom provocation to cognitive-behavioral probes of cortico-striatal systems and the amygdala. Neuroimage. 1996;4(3 Pt 3):S127-38.

78. Ellison Z, Foong J, Howard R, Bullmore E, Williams S, Treasure J. Functional anatomy of calorie fear in anorexia nervosa. Lancet. 1998;352:1192.

79. Rothemund Y, Buchwald C, Georgiewa P, Bohner G, Bauknecht HC, Ballmaier $\mathrm{M}$, et al. Compulsivity predicts fronto striatal activation in severely anorectic individuals. Neuroscience. 2011;197:242-50.

80. Kerr KL, Moseman SE, Avery JA, Bodurka J, Simmons WK. Influence of Visceral Interoceptive Experience on the Brain's Response to Food Images in Anorexia Nervosa. Psychosomatic medicine. 2017;79(7):777-84.

81. Brooks SJ, Owen GO, Uher R, Friederich HC, Giampietro V, Brammer M, Williams SC, Schiöth HB, Treasure J, Campbell IC. Differential neural responses to food images in women with bulimia versus anorexia nervosa. PLoS One. 2011;6(7):e22259.

82. Nagamitsu S, Yamashita F, Araki Y, lizuka C, Ozono S, Komatsu H, et al. Characteristic prefrontal blood volume patterns when imaging body type, high-calorie food, and mother-child attachment in childhood anorexia nervosa: A near infrared spectroscopy study. Brain Dev. 2010;32(2):162-7.

83. Boehm I, King JA, Bernardoni F, Geisler D, Seidel M, Ritschel F, et al. Subliminal and supraliminal processing of reward-related stimuli in anorexia nervosa. Psychol Med. 2018;48(5):790-800.

84. Kim KR, Ku J, Lee J-H, Lee $H$, Jung Y-C. Functional and effective connectivity of anterior insula in anorexia nervosa and bulimia nervosa. Neurosci Lett. 2012;521(2):152-7.

85. Uher R, Brammer MJ, Murphy T, Campbell IC, Ng WW, Williams SCR, Treasure J. Recovery and Chronicity in Anorexia Nervosa: Brain Activity Associated with Differential Outcomes. Biol Psychiatry. 2003;54(9):934-42.

86. Uniacke B, Timothy Walsh B, Foerde K, Steinglass J. The Role of Habits in Anorexia Nervosa: Where We Are and Where to Go From Here? Curr Psychiatry Rep. 2018;20(8):61.

87. Jiang T, Soussignan R, Schaal B, Royet JP. Reward for food odors: an fMRI study of liking and wanting as a function of metabolic state and BMI. Soc Cogn Affect Neurosci. 2015;10(4):561-8.
88. Born JM, Lemmens SG, Martens MJ, Formisano E, Goebel R, WesterterpPlantenga MS. Differences between liking and wanting signals in the human brain and relations with cognitive dietary restraint and body mass index. Am J Clin Nutr. 2011:94(2):392-403.

89. Cacioppo JT, Petty RE. Electromyograms as measures of extent and affectivity of information processing. Am Psychol. 1981;36(5):441-56.

90. Turner $\mathrm{R}$, Jones T. Techniques for imaging neuroscience. Br Med Bull. 2003; 65(1):3-20.

91. Hess U. facial eMG. Methods in social neuroscience. 2009:70-91.

92. Hare TA, Malmaud J, Rangel A. Focusing attention on the health aspects of foods changes value signals in vMPFC and improves dietary choice. J Neurosci. 2011;31(30):11077-87.

93. Schonberg T, Bakkour A, Hover AM, Mumford JA, Nagar L, Perez J, Poldrack RA. Changing value through cued approach: an automatic mechanism of behavior change. Nat Neurosci. 2014;17(4):625-30.

94. Turton R, Bruidegom K, Cardi V, Hirsch CR, Treasure J. Novel methods to help develop healthier eating habits for eating and weight disorders: A systematic review and meta-analysis. Neurosci Biobehav Rev. 2016;61:132-55.

95. Lawrence NS, O'Sullivan J, Parslow D, Javaid M, Adams RC, Chambers CD, et al. Training response inhibition to food is associated with weight loss and reduced energy intake. Appetite. 2015;95:17-28.

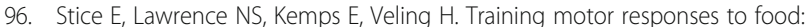
A novel treatment for obesity targeting implicit processes. Clin Psychol Rev. 2016;49:16-27.

97. Veling H, Lawrence NS, Chen Z, van Koningsbruggen GM, Holland RW. What Is Trained During Food Go/No-Go Training? A Review Focusing on Mechanisms and a Research Agenda. Curr Addict Rep. 2017;4(1):35-41.

98. Bakkour A, Foerde K, Schonberg T, Shadlen M, Walsh BT, Steinglass J, Shohamy D, editors. Cognitive mechanisms of decision making in anorexia nervosa. Society for Biological Psychiatry Annual Meeting; 2018; New York.

99. Kissileff HR, Brunstrom JM, Tesser R, Bellace D, Berthod S, Thornton JC, Halmi K. Computerized measurement of anticipated anxiety from eating increasing portions of food in adolescents with and without anorexia nervosa: Pilot studies. Appetite. 2016;97:160-8.

100. Milos G, Baur V, Schumacher S, Kuenzli C, Schnyder U, Mueller-Pfeiffer C, Martin-Soelch C. How fat will it make me? Estimation of weight gain in anorexia nervosa. Appetite. 2017:114:368-73.
Ready to submit your research? Choose BMC and benefit from:

- fast, convenient online submission

- thorough peer review by experienced researchers in your field

- rapid publication on acceptance

- support for research data, including large and complex data types

- gold Open Access which fosters wider collaboration and increased citations

- maximum visibility for your research: over $100 \mathrm{M}$ website views per year

At BMC, research is always in progress.

Learn more biomedcentral.com/submission 